\title{
De novo CD5-positive Diffuse Large B-cell Lymphoma of the Temporal Bone Presenting with an External Auditory Canal Tumor
}

\author{
Shoko Ogawa, Isao Tawara, Satoshi Ueno, Miho Kimura, Kana Miyazaki, \\ Hiroyoshi Nishikawa, Motoko Yamaguchi, Tohru Kobayashi and Hiroshi Shiku
}

\begin{abstract}
We report a 74-year-old woman with primary CD5-positive diffuse large B-cell lymphoma (DLBCL) of the temporal bone. The patient was admitted because of a mass in the left external auditory canal. She was treated with eight courses of CEOP therapy (rituximab was added from the sixth course) followed by radiotherapy of $40 \mathrm{~Gy}$, and complete remission was achieved. The occurrence of malignant lymphoma in the temporal bone, which is an extremely unusual site, may have depended on the peculiarity of CD5-positive DLBCL.
\end{abstract}

Key words: primary lymphoma of bone (PLB), temporal bone, external auditory canal, diffuse large B-cell lymphoma (DLBCL), CD5

(DOI: 10.2169/internalmedicine.45.1671)

\section{Introduction}

Primary lymphoma of bone (PLB) is a rare disease that accounts for $1-2 \%$ of all malignant lymphoma and $3-5 \%$ of all extranodal lymphoma (1), and initial involvement of the temporal bone is even rarer. The most common sites involved in PLB are the extremities, particularly the femur (13). Diffuse large B-cell lymphoma (DLBCL) is the most commom type of malignant lymphoma, representing 30-40\% of adult cases, and is regarded as a heterogeneous group of lymphoma in surface markers, histology, and clinical features $(4,5)$.

CD5 is a cell surface molecule expressed on most T cells and a subset of B cells. Among B-cell malignancies, CD5 is mainly expressed in chronic lymphocytic leukemia (CLL) and mantle cell lymphoma (MCL). Recently, CD5-positive DLBCL with no past history of lymphoproliferative disorder (de novo $\mathrm{CD} 5^{+} \mathrm{DLBCL}$ ) is regarded as a distinct subtype of DLBCL (6-8). De novo CD5 ${ }^{+}$DLCL, accounting for approximately $10 \%$ of DLBCLs, is characterized by elderly onset, female predominance, frequent involvement of a variety of extranodal sites, frequent association of international prognostic index (IPI) (9), and aggressive clinical course (6). Here, we describe a case of primary $\mathrm{CD} 5^{+}$DLBCL of the temporal bone with an external auditory canal mass and review the literature.

\section{Case Report}

A 74-year-old Japanese woman was referred to our hospital because of a left external auditory canal mass in June 2003. Six months before admission she complained of left ear fullness, and she was treated as left otitis media. The disease did not respond to treatment and swelling developed in the left external auditory canal. She had no history of lymphoproliferative disorder.

On admission, the patient was fully conscious and her performance status (PS) was 0 . Her temperature was $37.4^{\circ} \mathrm{C}$. On physical examination she showed slight swelling without tenderness in the left temporal region. Superficial lymph nodes were not palpable, and no abnormal findings were seen in either the chest or abdomen except for the presence of a systolic ejection murmur on cardiac auscultation. There were no abnormal findings on neurological examinations. She had no B symptoms (fever, night sweats and weight 

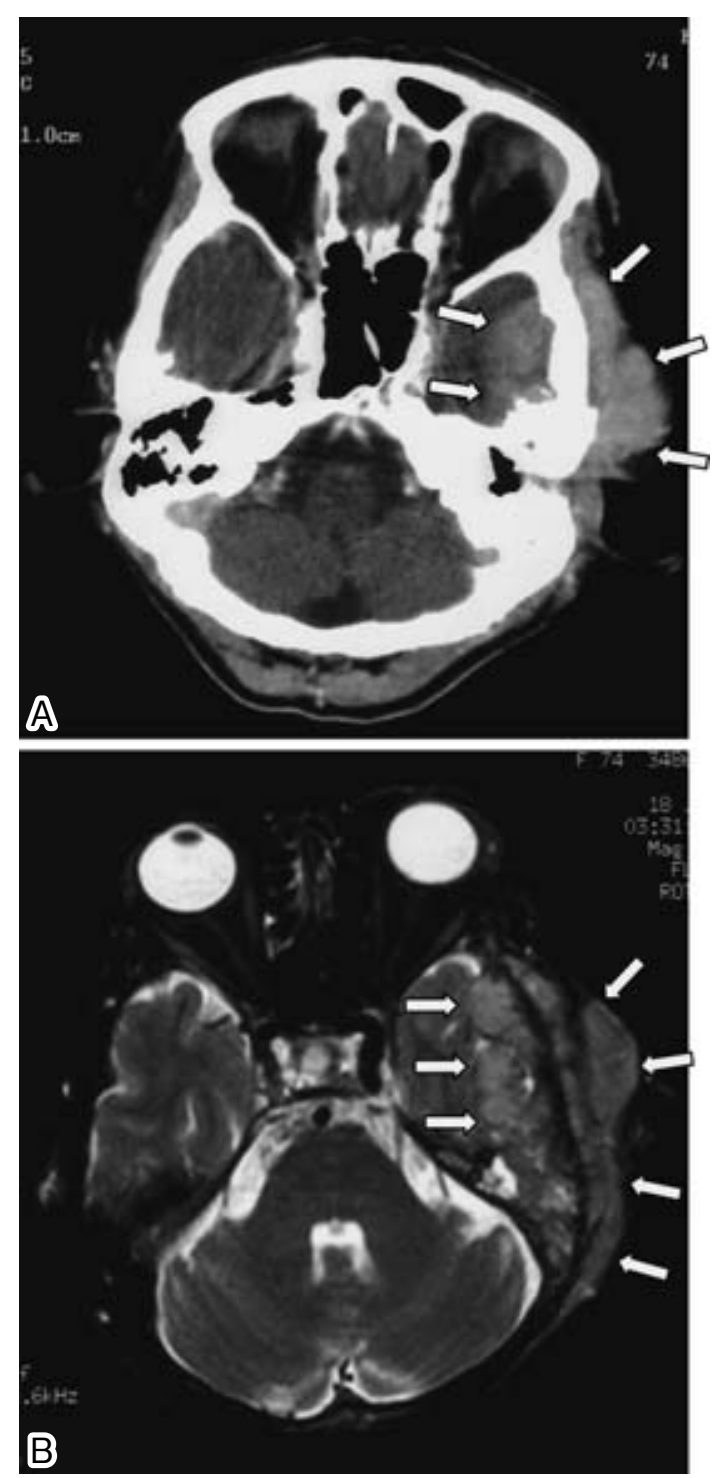

Figure 1. A) Soft tissue window CT showed an enhanced mass in the left temporal muscle, the lateral pterygoid muscle, the middle fossa, the mastoid air cells, and the middle ear (arrows). B) Axial T2-weighted MRI showed a mass (arrows) destroying the left temporal bone, with involvement of the overlying temporal muscle, subcutaneous tissue, and subdural space.

loss) according to the Ann Arbor classification.

Laboratory studies on admission showed a red blood cell count of $349 \times 10^{4} / \mathrm{mm}^{3}$, hemoglobin level of $10.2 \mathrm{~g} / \mathrm{dl}$, hematocrit of $30.6 \%$, white blood cell count of $4,390 / \mathrm{mm}^{3}$, and platelet count of $22.4 \times 10^{4} / \mathrm{mm}^{3}$. Serum lactate dehydrogenase (LDH) level was $226 \mathrm{IU} / \mathrm{ml}$, and was within normal limits (normal range, 100-230 IU/ml). C-reactive protein (CRP) was $0.46 \mathrm{mg} / \mathrm{dl}$ (normal value less than $0.30 \mathrm{mg} / \mathrm{dl}$ ). Soluble interleukin 2 receptor (sIL-2R) was slightly increased to $613.2 \mathrm{U} / \mathrm{ml}$ (normal range, 145.0-518.0 U/ml). Both anti-hepatitis $\mathrm{C}$ virus antibody and anti-human immunodeficiency virus antibody were negative. Serum EpsteinBarr virus (EBV)-specific antibodies suggested past infection. A bone marrow aspiration and biopsy showed hypocel-

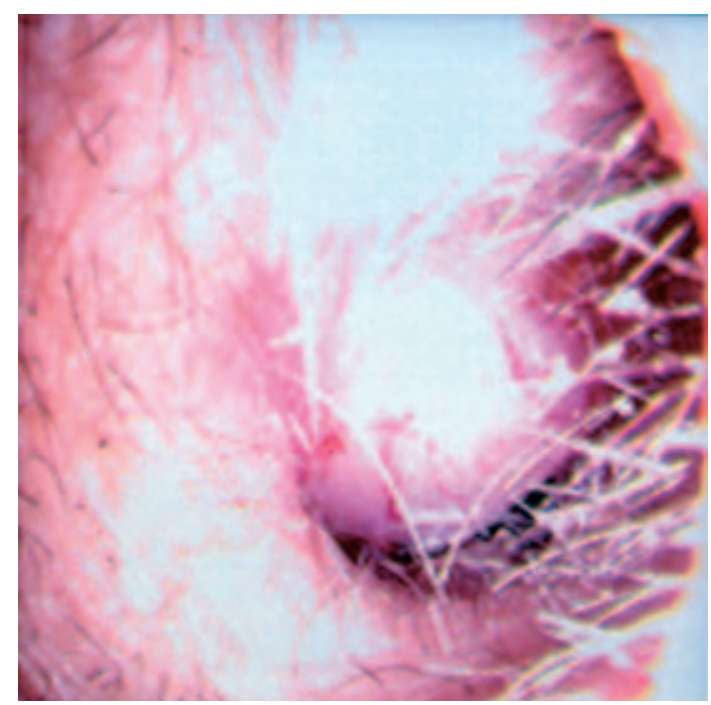

Figure 2. Otoscopic examination revealed a soft mass from the upper wall of the left external auditory canal.

lular bone marrow without atypical cells infiltration. Cerebrospinal fluid examination, and lung and abdominal computed tomography (CT) scans were normal.

CT scanning of the head showed an enhanced mass spreading through both sides of the left temporal bone with involvement of the mastoid air cells and the middle ear (Fig. 1A). ${ }^{67} \mathrm{Ga}$ scintigraphy showed increased uptake only in the left temporal region. Magnetic resonance imaging (MRI) of the head revealed a mass destroying the left temporal bone, with involvement of the overlying temporal muscle, subcutaneous tissue, lateral pterygoid muscle, and subdural space. The mass lesion showed low signal intensity on T1-weighted images, and high irregular signal intensity on T2-weighted images (Fig. 1B).

An audiogram revealed a combined hearing loss in the left ear and a perceptive hearing loss in the right ear. Otoscopic examination revealed a soft pink to white mass with a smooth outer surface from the upper wall that was obstructing the left external auditory canal (Fig. 2). The tympanic membrane was normal. Biopsy specimens of the mass showed diffuse proliferation of abnormal large lymphoid cells (Fig. 3A). Immunohistochemical staining using frozen sections showed that the lymphoma cells were positive for CD5, CD20, CD21, and negative for CD3, CD10, CD23, BCL2, and cyclin D1 (Fig. 3BCD). Tumor cells expressed surface Ig G- $\kappa$.

She was diagnosed as having primary $\mathrm{CD} 5^{+} \mathrm{DLBCL}$ of the temporal bone at clinical stage I EA with low-risk category of IPI (9). She was treated with CEOP chemotherapy consisting of cyclophosphamide at $750 \mathrm{mg} / \mathrm{m}^{2}$ on day 1, epirubicin at $50 \mathrm{mg} / \mathrm{m}^{2}$ on day 1 , vincristine at $1.4 \mathrm{mg} / \mathrm{m}^{2}$ on day 1 , and prednisolone at $100 \mathrm{mg} /$ body on days $1-5$. From the sixth course, rituximab was added on day 1 of CEOP. She was discharged in October 2003 and treated as an outpatient from the seventh course. After eight courses of chemotherapy, she was treated with local radiotherapy of $40 \mathrm{~Gy}$ and 


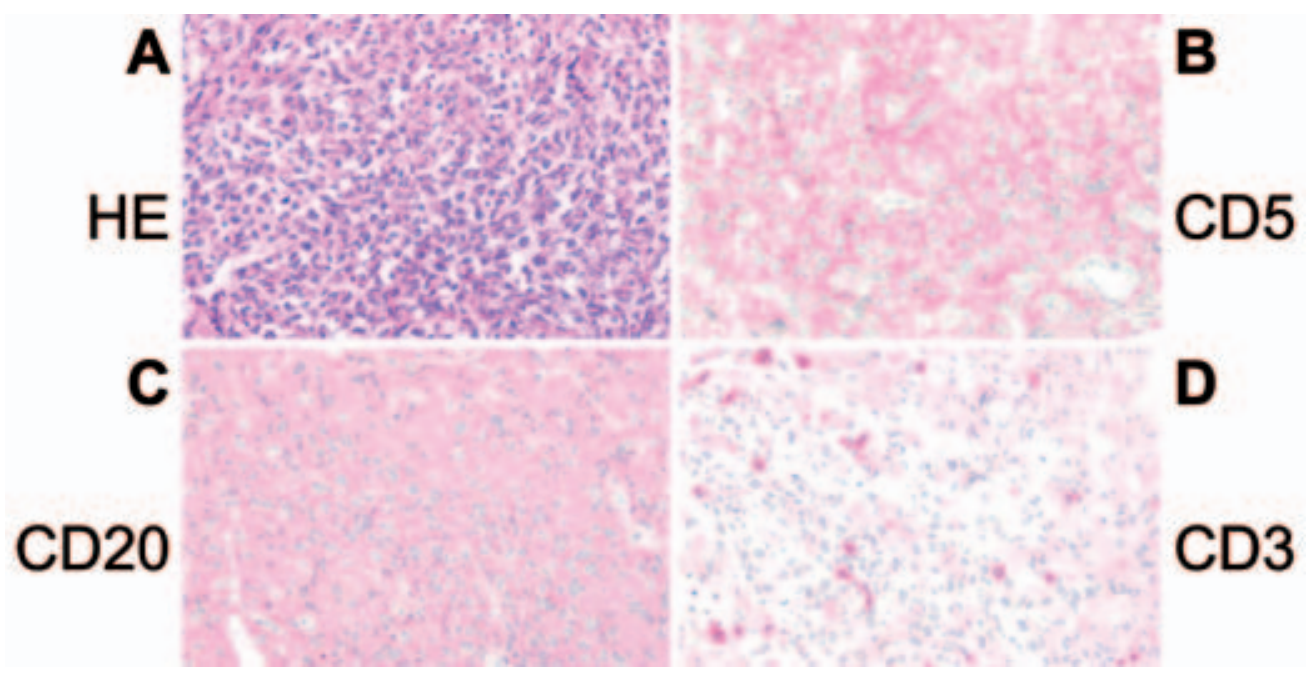

Figure 3. Histology of the tumor from the left external auditory canal. A) Diffuse infiltration of large-sized lymphoid cells was shown (Hematoxylin-eosin (HE) stain, ×200). B), C), D) Tumor cells were positive for CD5 and CD20, and negative for $\mathrm{CD3}(\times 200)$.

Table 1. Summary of Primary Lymphoma of the Temporal Bone

\begin{tabular}{|c|c|c|c|c|c|c|c|c|}
\hline Case No. & Age (year) & Sex & Histology & immune & Initial symptom & Therapy & Outcome & Reference \\
\hline 1 & 6 & M & lymphocytic & - & otorthea, mass from the external canal & $\mathbf{s}$ & Relapse, lost & 13 \\
\hline 2 & 66 & M & fymphocytic & - & otalgia & CT & Dead & 14 \\
\hline 3 & 32 & F & nodular, histocytic & - & ear fulliness, tinnitus, hearing loss & S, RT, CT & Dead & 15 \\
\hline 4 & 7 & M & Burkitrs & - & swelling behind the ear & CT & Dead & 16 \\
\hline 5 & 6 & M & Burkitrs & B & otalgia, low grade fever, loss of balance & $\mathrm{S}, \mathrm{CT}$ & Alive & 17 \\
\hline 6 & 66 & M & diffuse large cell & B & hearing loss, otalgia & S, CT RT & Dead & 18 \\
\hline 7 & 5 & M & diffuse large cell & B & otalgia, otorithea & ст & Alive & 18 \\
\hline 8 & 55 & M & pleomorphic & $T$ & ear fulliness & RT, CT & Dead & 19 \\
\hline 9 & 40 & M & diffuse smal & B & convulsiwe attack & RT, CT & Alive & 20 \\
\hline 10 & 2 & M & EBV+, high-grade B-cell lymphoma & B & otitis media, faclal palsy & S,CT & Alive & 21 \\
\hline 11 & 78 & M & large cell & - & mass in the temporal region & S, RT, CT & ND & 22 \\
\hline 12 & 66 & $\mathbf{F}$ & diffuse large cell, immunoblastic & B & ear fulliness & RT & Dead & 23 \\
\hline 13 & 16 & M & large cell, immunoblastic & T & pain in the skull, facial palsy & CT, RT & Dead & 24 \\
\hline 14 & 75 & M & large cell & B & otalgia, otorrhea, hearing loss & CT, RT & Alive & 25 \\
\hline 15 & 5 & M & bymphoblastic & B & facial palsy, hearing loss & CT & Alve & 26 \\
\hline 16 & 15 & M & diffuse histiocytic large cell & * & retroauricular mass & CT & Alve & 27 \\
\hline 17 & 81 & $F$ & DLBCL & B & abducens palsy, headache & CT, RT & ND & 28 \\
\hline 18 & 74 & $F$ & DLBCL & B & ear fulliness & CT, RT & Alve & $\begin{array}{c}\text { Present } \\
\text { case }\end{array}$ \\
\hline
\end{tabular}

S: surgery, CT: chemotherapy, RT: radiotherapy, ND: not described

achieved complete remission. She is alive and well without any therapy 33 months after the diagnosis.

\section{Discussion}

PLB is a rare disease accounting for $1-2 \%$ of all malignant lymphoma and 3-5\% of all extranodal lymphoma (1). The diagnostic criteria for PLB have been developed from those enumerated by Coley et al in 1950 and are as follows: 1) clinically a primary focus in a single bone on admission, 2) unequivocal histologic proof from the bone lesion, 3) metastases present on admission only if regional, or if the onset of symptoms of the primary tumor preceded the appearance of the metastases by at least six months (10). Currently, the criteria adopted by the World Health Organization are the following: 1) a single skeletal site, with or without regional lymph node involvement; 2) multiple bones are involved, but there is no visceral or lymph node involvement (11).

PLB may occur in patients of any age group but has a tendency of adult onset and a male predominance (male-tofemale ratio ranges from 1.5-2: 1) $(2,3,11)$. The most common initial symptom is localized pain, and patients sometimes present with a palpable mass $(1-3,10)$. Patients rarely present with systemic symptoms, such as fever or night sweating $(1,2,11)$. On conventional X-ray, PLB shows lytic, sclerotic, permeative lesions, or a combination of these (1). CT and MRI are useful for the diagnosis of PLB. However, on follow-up examinations, MRI is not useful to differentiate between persistent disease and healing bone (3). Positron emission tomography with fluorine 18- 
fluorodeoxyglucose (FDG-PET) may be preferable for the assessment of remission status. Histopathologically, PLB is usually diagnosed as DLBCL $(1-3,10,11)$. It is considered that PLB usually requires radiotherapy with chemotherapy (3). Generally, the prognosis of PLB is favorable, and the 5year overall survival is approximately $60 \%(2,11,12)$.

The most common sites involved in PLB are the extremities, particularly the femur (1-3), and initial involvement of the temporal bone is extremely rare. We found only 17 reported cases of primary temporal bone lymphoma in the English and Japanese literature, including the cases of primary lymphoma of the middle ear (13-28). A total of 18 cases (14 patients males, and 4 females), including the present case, are summarized in Table 1 . The age at diagnosis ranged from 2 to 81 years with a tendency to involve children and elderly ages. The most common initial symptoms were ear symptoms (12 of 18) such as otalgia, hearing loss, and ear fullness. Some patients presented with facial nerve palsy ( 3 of 18), or localized swelling (3 of 18). The temporal bone contains the sensory organs of hearing and balance (the inner ear, the middle ear, and the external auditory canal), and the facial nerve passes through the temporal bone. The symptoms of temporal bone lymphoma, such as ear symptoms and facial nerve palsy, are related to these anatomical features. On otoscopic examination, 5 patients, including our case, had a soft mass in the external auditory canal $(13,15,20,23)$. Immunophenotypic analysis was performed in 12 patients, and 10 out of 12 patients were B-cell type. The expression of CD5 was not examined in any previously reported case. Among 18 cases, 8 patients were alive, and 7 were dead, and it suggests that primary temporal bone lymphoma seems to be similar in prognosis to PLB.

On the other hand, there have been only 3 reported cases of primary lymphoma of the external auditory canal (29-31), and there was no bone destruction in these cases. Interestingly, 2 of 3 patients had bilateral tumors $(29,30)$ and one of these involved the use of hearing aids for a long period of time (29). There has been one other report of malignant lymphoma of the external auditory canal in a human immunodeficiency virus (HIV)-positive patient, but this originated in the infratemporal fossa and grew through the eustachian tube to present in the ear canal (32). Primary lymphoma of the inner ear is also extremely rare (33). Although biopsy of the bone lesion was not performed in our case, we considered the disease as primary temporal bone lymphoma based on CT and MRI findings that showed the mass lesion destroying the bone and spreading through both sides of the bone. However, it was not clear whether the primary site of the disease was the temporal bone or adjacent soft tissue.

CD5 ${ }^{+}$DLBCL is known to have clinicopathologically and genotypically different characteristics from CD5DLBCL (68). Patients with $C D 5^{+}$DLBCL show a high age at onset, a female predominance, frequent involvement of a variety of extranodal sites, and poor overall prognosis with a 5-year survival rate of $34 \%$ (6). High age, female sex, and involvement of an extranodal site in our patient all match the clinical features of $\mathrm{CD}^{+} \mathrm{DLBCL}$. In our case, the occurrence of DLBCL in the temporal bone, which is an extremely unusual site, may have depended on the peculiarity of $\mathrm{CD5}^{+}$ DLBCL. Though our patient achieved complete remission, she will need careful follow-up hereafter.

We report a rare case of primary temporal bone lymphoma. Our case and a review of the literature show that malignant lymphoma should be taken into consideration as a differential diagnosis in cases of therapy-resistant ear disease.

\section{References}

1. Dubey P, Ha CS, Besa PC, et al. Localized primary malignant lymphoma of bone. Int J Radiat Oncol Biol Phys 37: 1087-1093, 1997.

2. Ostrowski ML, Unni KK, Banks PM, et al. Malignant lymphoma of bone. Cancer 58: 2646-2655, 1986.

3. Baar J, Burkes RL, Bell R, Blackstein ME, Fernandes B, Langer F. Primary non-Hodgkin's lymphoma of bone. A clinicopathologic study. Cancer 73: 1194-1199, 1994.

4. Harris NL, Jaffe ES, Stein H, et al. A revised European-American classification of lymphoid neoplasms: a proposal from the International Lymphoma Study Group. Blood 84: 1361-1392, 1994.

5. Gatter KC, Warnke RA. Diffuse large B-cell lymphoma. in: World Health Organization Classification of Tumours: Pathology and Genetics of Tumours of Haematopoietic and Lymphoid Tissues. Jaffe ES, Harris NL, Stein H, Vardiman JW, eds. International Agency for Research on Cancer (IARC) Press, Lyon, France, 2001: 171174.

6. Yamaguchi M, Seto M, Okamoto M, et al. De novo $\mathrm{CD}^{+}$diffuse large B-cell lymphoma: a clinicopathologic study of 109 patients. Blood 99: 815-821, 2002.

7. Kobayashi T, Yamaguchi M, Kim S, et al. Microarray reveals differences in both tumors and vascular specific gene expression in de novo $\mathrm{CD}^{+}$and $\mathrm{CD}^{5}$ diffuse large B-cell lymphomas. Cancer Res 63: 60-66, 2003.

8. Tagawa H, Suguro M, Tsuzuki S, et al. Comparison of genome profiles for identification of distinct subgroups of diffuse large Bcell lymphoma. Blood 106: 1770-1777, 2005.

9. The International Non-Hodgkin's Lymphoma Prognostic Factors Project. A predictive model for aggressive non-Hodgkin's Lymphoma. N Engl J Med 329: 987-994, 1993.

10. Coley BL, Higinbotham NL, Groesbeck HP. Primary reticulumcell sarcoma of bone. Summary of 37 cases. Radiology 55: 641658, 1950.

11. Unni KK, Hogendoorn PCW. Malignant lymphoma. in: World Health Organization Classification of Tumours: Pathology and Genetics of Tumours of Soft Tissue and Bone. Fletcher CDM, Unni KK, Mertens F, eds. International Agency for Research on Cancer (IARC) Press, Lyon, France, 2002: 306-308.

12. Heyning FH, Hogendoorn PC, Kramer MH, et al. Primary nonHodgkin's lymphoma of bone: a clinicopathological investigation of 60 cases. Leukemia 13: 2094-2098, 1999.

13. Malik MK, Gupta RK, Samuel KC. Primary lymphoma of middle ear - a case report. Indian J Cancer 13: 188-189, 1976.

14. Harner SG, Olsen KD, Banks PM, O'Connell MJ. Lymphocytic 
lymphoma involving the middle ear. Mayo Clin Proc 55: 645-647, 1980.

15. Gapany-Gapanavicius B, Chisin R, Weshler Z. Primary presentation of malignant lymphoma in middle ear cleft. Ann Otol Rhinol Laryngol 89: 180-183, 1980.

16. Oyetunji NM, Ladapo AA. Burkitt's lymphoma of the mastoid temporal bone. J Laryngol Otol 95: 1063-1067, 1981.

17. Welling DB, McCabe BF. American Burkitt's lymphoma of the mastoid. Laryngoscope 97: 1038-1042, 1987.

18. Tucci DL, Lambert PR, Innes DJ Jr. Primary lymphoma of the temporal bone. Arch Otolaryngol Head Neck Surg 118: 83-85, 1992.

19. Ide M, Matsuura K, Imuta M. Primary malignant lymphoma of middle ear. Otol Jpn 3: 199-202, 1993 (in Japanese, Abstract in English).

20. Noguchi H, Motizuki T, Kamata T, Ogawa Y, Ueno Y. Primary malignant lymphoma in the temporal bone -report of a case. Jibi Inkoka, Tokeibu Geka 65: 757-760, 1993 (in Japanese, Abstract in English).

21. Bockmühl U, Bruchhage KL, Enzmann H. Primary non-Hodgkin's lymphoma of the temporal bone. Eur Arch Otorhinolaryngol 252: 376-378, 1995.

22. Paige ML, Bernstein JR. Transcalvarial primary lymphoma of bone. A report of two cases. Neuroradiology 37: 456-458, 1995.

23. Saigusa H, Akimoto R, Ryu A, et al. Malignant lymphoma of the temporal bone. Jibi Inkoka, Tokeibu Geka 69: 233-238, 1997 (in Japanese, Abstract in English).

24. Danino J, Joachims HZ, Ben-Arieh Y, Hefer T, Weyl-Ben-Arush
M. T cell lymphoma of the ear presenting as mastoiditis. J Laryngol Otol 111: 852-854, 1997.

25. Merkus P, Copper MP, Van Oers MH, Schouwenburg PF. Lymphoma in the ear. ORL J Otorhinolaryngol Relat Spec 62: 274277, 2000.

26. Lang EE, Walsh RM, Leader M. Primary middle-ear lymphoma in a child. Laryngol Otol 117: 205-207, 2003.

27. Koral K, Curran JG, Thompson A. Primary non-Hodgkin's lymphoma of the temporal bone. CT findings. Clin Imaging 27: 386388, 2003.

28. Chang CY, O'Halloran EK, Fisher SR. Primary non-Hodgkin's lymphoma of the petrous bone: case report. Otolaryngol Head Neck Surg 130: 360-362, 2004.

29. Maiche AG, Teerenhovi L, Isokangas O. Diffuse centrocytic malignant lymphoma with unusual sites--report on two cases with possible etiological factors. Acta Oncol 30: 767-768, 1991.

30. Shuto J, Ueyama T, Suzuki M, Mogi G. Primary lymphoma of bilateral external auditory canals. Am J Otolaryngol 23: 49-52, 2002.

31. Fish BM, Huda R, Dundas SA, Lesser TH. B-cell lymphoma of the external auditory meatus. J Laryngol Otol 116: 39-41, 2002.

32. Kieserman SP, Finn DG. Non-Hodgkin's lymphoma of the external auditory canal in an HIV-positive patient. J Laryngol Otol 109: $751-754,1995$.

33. Angeli SI, Brackmann DE, Xenellis JE, Poletti BJ, Carberry JN, Hitselberger WE. Primary lymphoma of the internal auditory canal. Case report and review of the literature. Ann Otol Rhinol Laryngol 107: 17-21, 1998.

(C) 2006 The Japanese Society of Internal Medicine http://www.naika.or.jp/imindex.html 